\title{
Family Satisfaction towards Care Provided to Criticaly Ill Patients and Associated Factors in the ICU of Governmental Hospitals of Addis Ababa Town, 2017
}

\author{
Girum Sebsibie Teshome*, Nitsuhbirhan Asres Roge, Yohannis Ayalew Ayalew and Asnakech Sisay Sibany
}

Addias Ababa university, Addis Ababa, Ethiopia

\begin{abstract}
Background: Intensive care unit is a consolidated area which needs high quality of care and follows up of patients with more sofesticated equipments. Assessment of satisfaction is one indicator to determine quality of care given for the patients. In the ICU patients are not in the condition to give their opinion about the care; therefore assessment of family satisfaction in care of critically ill patients can be important indicator of quality of care in critical care unit.

Method: Institutional based cross sectional study conducted in five hospitals ICU found in Addis Ababa, Ethiopia. The total sample size was 206 and allocated using stratified sampling method. By reviewing letreture major satisfaction predictors were identified and likert scale were used to assess the satisfaction level of participants and data was collected by interviewer administered structured questioner. The result was entered, cleaned and coded Epi data 3.1 and transferred to spss versio 21 windows for analysis.

Result: Over all satisfaction of families by care given to ICU patients were $62 \%$. Age less than 25 and between 25 and 35 by (AOR-1.282, 95\% Cl 0.081-0.095) and (AOR - 1.277, 95\% Cl 0.82-0.943) respectively, also education below grade eight (AOR $1.11295 \% \mathrm{Cl} 1.170-7.909$ ) associated with higher family satisfaction. Families who have no information about patients condition and families of patients with poor progress respectively had less odds of satisfaction.
\end{abstract}

Conclusion: The overall family satisfaction is moderate. From the satisfaction predictors families were less satisfied on availability of waiting area and information give by the health professionals.

Keywords: ICU; Head injury; Health

Abbreviations: AAU: Addis Ababa University; CCFNI: Critical Care Family Need Indicator; FMOH: Federal Ministry of Health

\section{Introduction}

Intensive care unit is a special department of hospitals which is responsible to care for seriously ill patients. Patients in the ICU needs constant close monitoring from specialist and nurses with supportive equipments and medication [1]. The reason for admission world wide is different, the most common reason in Africa is head injury followed by respiratory failure, sepsis and obstetric couses [2-4]. ICU mortality rate in developed countries accounts $8 \%$ to $20 \%$. Amoung all deaths, the ICU mortality rate accounts $20 \%$ in US, between $30 \%$ to $50 \%$ in africa. From east african countries a study in Uganda indicates $25 \%$ to $68 \%$ of death from medical and surgical ICU and $37.7 \%$ death in one referral hospital in Ethiopia [5-7].

The patient treatment outcame affected by seriousness of illness and quality of care given for the patients. Patients perception about healthcare has been predominantly accepted as an important indicator for measuring quality of health care and a critical component of performance improvement and clinical effectiveness [7].

Critically ill patients can not make their own decision or their openion about the health care service due to the seriousness of illness patients become unconscious or may stay on mechanical ventilation. ICU patients family members play critical role in daily descison making. Families satisfaction considered as an important indicator for assessing quality of care in the intensive care unit. Different studies shows that more common family satisfaction predictors are in need of information, support, proximity and comfort for patients and thier family members $[8,9]$.
A study conducted in countries like Canada, Portugal, Morocco shows families of patients are more satisfied on participation of families in descision making, the nurses skill and competancy, information, emotional and physical suppot also less satisfaction on the families waiting area and the support given for the families [10-23].

Family members are in continuous need of knowing their relatives well being and if the patient is getting the best possible care from the health care team. Meeting the need of families can lead them to be satisfied by the care given to the patient [15].

When families are satisfied with the service given it increase their trust on the medical team the refusal of family to stay in the hospital or discharge of patient against the medical advice will be decreased additionally families became ready to accept the patients poor out came whether it is disabilit y or death.

In africa, there is no many study which is conducted about ICU patients family satisfaction service quality. Also no researches done in Ethiopia which assess the level of family satisfaction abou the care given to patients in the intensive care unit. The purpose of this research is to assess the satisfaction level of families admitted in adult and neonatal ICU and factors associated with the level of satisfaction.

*Corresponding author: Girum Sebsibie Teshome, Addias Ababa university, Addis Ababa, Ethiopia, Tel: 251111239746; E-mail: girumseb@gmail.com

Received June 26, 2018; Accepted August 14, 2018; Published August 18, 2018

Citation: Teshome GS, Roge NA, Ayalew YA, Sibany AS (2018) Family Satisfaction towards Care Provided to Criticaly III Patients and Associated Factors in the ICU of Governmental Hospitals of Addis Ababa Town, 2017. J Trauma Treat 7: 429. doi: 10.4172/2167-1222.1000429

Copyright: (c) 2018 Teshome GS et al. This is an open-access article distributed under the terms of the Creative Commons Attribution License, which permits unrestricted use, distribution, and reproduction in any medium, provided the original author and source are credited. 


\section{Materials and Methods}

\section{Study design and period}

An institutional based descriptive cross-sectional study was conducted to assess family satisfaction in care of critically ill patient from january to june 2017 and the data collection period was from april to may 2017.

\section{The study area}

The study was conducted in Addis Ababa, the capital city of Ethiopia. Addiss Ababa has a population size of over 3 million with annual growth rate of $2.1 \%$ (Data obtained from central stastical agency of Ethiopia). The city has 35 private and 13 public hospitals. Among this five of them provides intensive care unit service. Totally there is 22 adult and 140 neontal ICU beds. Average per month, 367 patients were treated in the hospitals intensive care unit.

\section{Source and study population}

Source population was all families of admitted patients with in selected hospitals during the study period and families of patients who were available in the intensive care units in the study hospitals at the time of data collection and who meets the inclusion criteria considered as study population.

\section{Inclusion criteria}

A patients who stayed at least two days in the ICU and the patient relatives who have more than three visit and responsible in caring for the patient and also being 18 years or older was the inclusion criteria. Also only one patient family for one selected patient was included.

\section{Sample size determination}

Actual sample size for the study computed using single population proportion formula $(n=[(Z \alpha / 2) 2 \times P(1 P)] / D 2)$ by assumption of $5 \%$ marginal error, $95 \%$ confidence interval of certainty (alpha= 0satisfaction.05) $50 \%$ prevalence of family satisfaction in care of critically ill patient since there is no previous similar study. After calculating the sample size population reduction formula $n=n /\left(1+\frac{n}{N}\right)$ due to the source population were 367 . Final calculated sample size by adding $10 \%$ non-respondent rate became 206 . The total sample size was allocated proportionally to five hospitals adult and neonatal ICU. Using the study population in each hospitals ICU sample was allocated proportionally using stratified sampling method. The study units identified and the study sample that meet the inclusion criteria was taken from units under study. The allocated sample was selected using systematic random sampling method. In each hospital every 2 participants were interviewed using the patient's admission registrations book.

\section{Depandent and independent variables}

The dependent variable is family satisfaction and age, sex, income, education, patient condition, families past experience in ICU and the ICU unit and the independent variable were family satisfaction.

\section{Data collection tool and proceduer}

After reviewing different literatures, major variables identified aefing accordibg to the Ethiopian situation. It contains two parts which contains sociodemographic character and questions which assesses the level of family satisfaction. An interviewer administered structured questioner administered to participant about their satisfaction on various aspectes of critical care. The quetsione uses likert scale from
1 to 5 . One is not at all satisfied, two barely satisfied, 3 quite satisfied, 4 very satisfied and 5 completely satisfied. The higer score and lower score is 105 and 25 respectively. They informed to select only on number that best describes their openion on each item of the scale. The data collected from the study hospitals by diploma nurses who are not involved in patient care.

\section{Data quality assurance}

The data collection tool translated in to local languge (amharic). The second version of the tool was back translated in to the English to evaluate its consistencey and before the actual data collection pretest on $5 \%$ of the sample was done. Based on the finding of the pretest some modification was done. Training to data collector was given and the coordinator checks the completeness of the questioner immediately after submission.

\section{Operational definitions}

- Satisfied: Refers to participant who respond greater than mean level of satisfaction.

- Not satisfied: Refers to participants who respond as less than mean level of satisfaction.

\section{Data processing and analysis procedures}

Data entered into EPI data version 3.1 and exported to SPSS version 21. Then the data were transferred and analyzed by SPSS software package. The descriptive analysis suchas frequency distribution, proportions, percentages, and measures of central tendency isused. Bivariate and multivariate analysis with alpha $=0.05$ performed to measureassociation of satisfaction by different variables. The result was presented using tables, graph and diagrams. Satisfaction is classified as satisfied and not satisfied by using meanscore value.

\section{Data processing and analysis procedure}

Data entered in to EPI data version 3.1 and exported to SPSS version 21. Then the data were transferred and analysed by SPSS software package. The descriptive analysis such as frequency distribution, proportions.

\section{Results}

\section{Characteristics of the respondent}

From the sample size of 206 respondents 202 (98\%) were participated in the interview. Majority of respondents were females, married, parents and income less than $1000^{\text {eth }}$ birr. Mean age of participants were (27, 7SD 7.30). Listed in Table 1 below.

\section{Socio demographic characteristics of the respondent}

From the sample size of 206 respondents 202 (98\%) were participated in the interview. Majority of respondents were females, married, parents and income less than $1000^{\text {eth }}$ birr. Mean age of participants were (27,7SD 7.30). Listed in Table 1.

More than tree fourth (79\%) of respondents were from neonatal ICU. The mean duration of stay in the ICU was (8.12 SD 9.28) days. About $95.5 \%$ of families had no previous experience in the ICU. Among families, $71.8 \%$ of them respond as the patient had good progress.

Level of family satisfaction in care of critically ill patient in the intensive care unit

The overall satisfaction level of respondents was $62.9 \%$ (67 SD 


\begin{tabular}{|c|c|c|c|}
\hline \multicolumn{2}{|c|}{ Demographic character } & Frequency & $\%$ \\
\hline \multirow{3}{*}{ Age of respondent } & $\leq 25$ & 90 & 44.6 \\
\hline & $25-35$ & 88 & 43.6 \\
\hline & $>35$ & 24 & 11.9 \\
\hline \multirow{2}{*}{ Sex of participant } & Male & 48 & 23.8 \\
\hline & Female & 154 & 76.2 \\
\hline \multirow{4}{*}{ Educational status } & No formal education & 39 & 19.3 \\
\hline & $1-8$ & 61 & 30.2 \\
\hline & $9-12$ & 51 & 25.2 \\
\hline & diploma $\%$ above & 51 & 25.2 \\
\hline \multirow{3}{*}{ Marital status } & Married & 171 & 84.7 \\
\hline & unmarried & 27 & 13.4 \\
\hline & Divorced & 4 & 2 \\
\hline \multirow{3}{*}{ Monthly income } & 1000 & 130 & 64.4 \\
\hline & $1000-2500$ & 43 & 21.2 \\
\hline & $>2500$ & 29 & 14.4 \\
\hline \multirow{3}{*}{ Relation with patient } & parent & 178 & 88 \\
\hline & partner & 3 & 1.5 \\
\hline & bro/sis & 21 & 10.4 \\
\hline \multirow{2}{*}{ Location of home } & Addis Ababa & 153 & 75.7 \\
\hline & Out of Addis & 49 & 24.3 \\
\hline
\end{tabular}

Table 1: Socio demographic characteristics of ICU patient's families from all Hospitals ICU Addis Ababa, June 2017.

11.78). The satisfaction level in neonatal unit were higher than families in adult ICU which is (63.8\% and 58.3\%). Also based on the families ICU experience, respectively. In neonatal ICU. Based on families experience in the ICU. Satisfaction level of families who had no experience in ICU were $63.2 \%$ while those who had previous experience in the ICU, was $55.6 \%$. The satisfaction of families related with the length of stay in the hospital indicated in the Figure 1 below.

Detail assessment of satisfaction based on identified indicators shows that majority of families (68.8\%) explains about difficulty of knowing the patients care giving nurse and unable to get explanation about tests, procedures and treatment given for the patients. Generally families were more satisfied by the support given by physician and nurses and least satisfied on information and comfortable waiting area. Summarized on Figure 2 below.

\section{Association of variable with satisfaction on the care given to participants in critical care unit}

In bivariate analysis, factors that found to have association with satisfaction were age, sex, educational status, monthly income, length of stay and patient condition at $\mathrm{p}$ less than 0.2 . This variables identified as predictor of family satisfaction in multivariate logistic regression model. In multivariate analysis age, education level and patient health condition had an association with the dependent variables. Age less than 25 by 0.21 times and between 25 to 35 by 0.22 times les odds of satisfaction as compared to age above 35 (AOR $0.21,95 \%$ CI $0.05-0.83$ ) and (AOR 0.22 95\% CI 0.06- 0.79) respectively.

Those who have primary education 3.13 times more satisfied than those who had diploma and above by (AOR 3.13, 95\% CI 1.16-8.43). Families who consider the patient health condition as deteriorated by $73 \%$ and those who had no information about the status of the patient were less satisfied than families who considered the patient status as improved (AOR 0.27 95\% CI, 0.11-0.66) and (AOR 0.12 95\% CI, 0.04$0.37)$ respectively. Displayed in the Table 2 below.

\section{Discussion}

This study shows the level of family satisfaction in care of critically
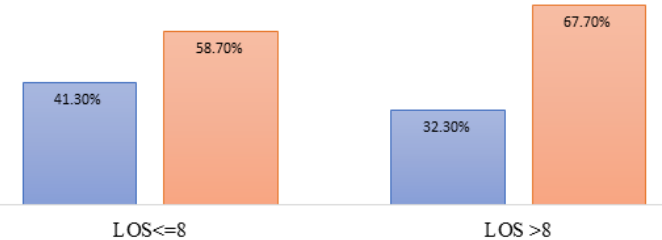

$\square$ disatisfied

$\square$ satisfied

Figure 1: Satisfaction of families based on patient's length of stay in the hospitals among hospitals ICU found in Addis Ababa Ethiopia, 2017.

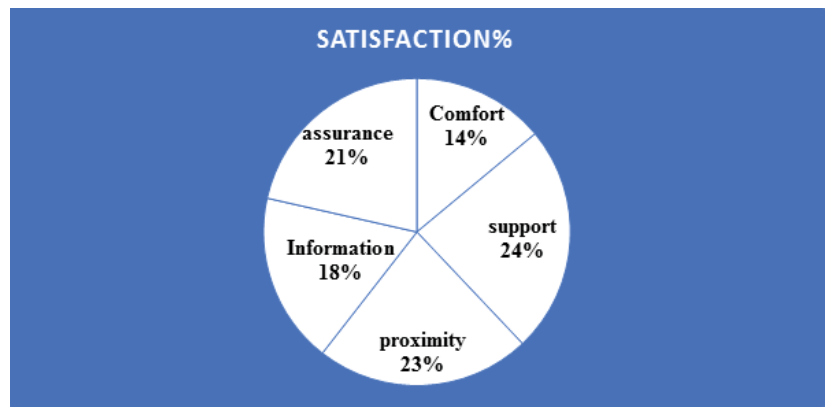

Figure 2: Satisfaction of families based on identified indicators in the hospitals among hospitals ICU found in Addis Ababa Ethiopia, 2017.

ill patients in ICU were $62 \%$ (67.7 SD 11.6). The satisfaction is lower than countries like Switzerland and Canada by mean sore of (78 SD $15)$ and (84.3 SD 15.7). This can be due to difference in advancement of technologies, availability of well-trained health professionals and the degree of quality of care given for patients and their family members.

Health professionals support and encouragement, their explanation of tests, procedures, treatment and willingness of staffs in sharing decision regarding the patient care and recovery on regular base were areas which families are least satisfied, Which is $20 \%(2.26$ SD 1-19), 26.6\% (2.59 SD 1.10) 34.2\% (2.66 SD 1.21) respectively. But study in Canada shows families satisfaction were high on similar variables by the mean of (4.74 SD 0.53), (4.71 SD 0.51) and (4.68 SD $0.65)$ respectively. In Morocco (81\%) of families are satisfied by the information given by Physicians. In this study families satisfaction on support and information were very law, it can be due to the minimum involvement of families in the care given to the patient, less knowledge and practice of health professionals about family centered care and not considering the right of families to get information. Also it can be related with high patient flow with less proportion of (PatientNurse) and (Patient-Physician) ratio. Families are least satisfied by the cleanness and appearance of waiting room $(31.7 \%)$ and its peacefulness and comfort for rest (36.9\%). This may be related with loss of adequate place for waiting at a day and night time, difficulty of getting place for basic needs like (for serving, water and toilet). Similarly a study in Japan, Sweden and Canada shows families are list satisfied by waiting room atmosphere.

Variables significantly associated with satisfaction are age, education of families and patient health condition. Age less than 25 by 0.21 times and age 25-35 are 0.22 times less odds of satisfaction as compared to age above 35 (AOR 0.21, 95\% CI 0.05-0.83) and (AOR 0.22 , 95\% CI 0.06-0.79) respectively, but in research done in Greece 
Citation: Teshome GS, Roge NA, Ayalew YA, Sibany AS (2018) Family Satisfaction towards Care Provided to Criticaly III Patients and Associated Factors in the ICU of Governmental Hospitals of Addis Ababa Town, 2017. J Trauma Treat 7: 429. doi: 10.4172/2167-1222.1000429

\begin{tabular}{|c|c|c|c|c|}
\hline Variables & Not satisfied & Satisfied & COR $(95 \% \mathrm{Cl})$ & AOR (95\% C.I.) \\
\hline \multicolumn{5}{|c|}{ Age (year) } \\
\hline$\leq 25$ & $32(35.6 \%)$ & \begin{tabular}{c|}
58 \\
$(64.4 \%)$ \\
\end{tabular} & \begin{tabular}{|c|}
$0.477(0.163-$ \\
$1.398)$ \\
\end{tabular} & $\begin{array}{c}0.218(0.057- \\
0.835)^{*} \\
\end{array}$ \\
\hline $25-35$ & $38(43.2 \%)$ & $\begin{array}{c}50 \\
(56.8 \%) \\
\end{array}$ & \begin{tabular}{|c|}
$0.346(0.119-$ \\
$1.011)$ \\
\end{tabular} & $\begin{array}{c}0.223(0.062- \\
0.797)^{\star} \\
\end{array}$ \\
\hline$>35$ & $5(20.8 \%)$ & \begin{tabular}{c|}
19 \\
$(79.2 \%)$ \\
\end{tabular} & 1 & 1 \\
\hline \multicolumn{5}{|c|}{ Sex } \\
\hline Male & $23(47.9 \%)$ & $25(52 . \%)$ & \begin{tabular}{|c|}
$0.554(0.287-$ \\
$1.069)$ \\
\end{tabular} & $\begin{array}{c}0.494(0.202- \\
1.208) \\
\end{array}$ \\
\hline Female & $52(33.8 \%)$ & $\begin{array}{c}102 \\
(66.2 \%) \\
\end{array}$ & 1 & 1 \\
\hline \multicolumn{5}{|c|}{ Educational level } \\
\hline No formal education & $10(25.6 \%)$ & \begin{tabular}{c|}
29 \\
$(74.4 \%)$ \\
\end{tabular} & \begin{tabular}{|c|}
$3.530(1.427-$ \\
$8.736)$ \\
\end{tabular} & $\begin{array}{c}2.694(0.971- \\
7.472)^{\star}\end{array}$ \\
\hline Grade 1-8 & $16(26.2 \%)$ & \begin{tabular}{c|}
45 \\
$(73.8 \%)$ \\
\end{tabular} & \begin{tabular}{|c|}
$3.424(1.548-$ \\
$7.571)$ \\
\end{tabular} & $\begin{array}{c}3.131(1.163- \\
8.431)^{\star} \\
\end{array}$ \\
\hline Grade 9-12 & $21(41.2 \%)$ & $\begin{array}{c}30 \\
(58.8 \%) \\
\end{array}$ & $\begin{array}{c}1.739(0.79- \\
3.81) \\
\end{array}$ & $\begin{array}{c}1.514(0.580- \\
0.952) \\
\end{array}$ \\
\hline Diploma and above & $28(54.9 \%)$ & $\begin{array}{c}23 \\
(45.1 \%) \\
\end{array}$ & 1 & 1 \\
\hline \multicolumn{5}{|c|}{ Patient condition } \\
\hline Worsening & $20(55.6 \%)$ & \begin{tabular}{c|}
16 \\
$(44.4 \%)$ \\
\end{tabular} & \begin{tabular}{|c|}
$0.305(0.144-$ \\
$0.646)$ \\
\end{tabular} & $\begin{array}{c}0.27(0.114- \\
0.664)^{\star} \\
\end{array}$ \\
\hline Don't know & $15(71.4 \%)$ & $6(28.6 \%)$ & $\begin{array}{c}0.152(0.05- \\
0.42) \\
\end{array}$ & $\begin{array}{c}0.123(0.040- \\
0.378)^{*} \\
\end{array}$ \\
\hline Good progress & $40(27.6 \%)$ & $\begin{array}{c}105 \\
(72.4 \%) \\
\end{array}$ & 1 & 1 \\
\hline \multicolumn{5}{|c|}{ Relation with patient } \\
\hline Parent & $64(36.0 \%)$ & $114(64 \%)$ & $\begin{array}{c}1.33(0.444- \\
4.021) \\
\end{array}$ & $\begin{array}{c}1.359(0.426- \\
4.330) \\
\end{array}$ \\
\hline Partner & $5(50.0 \%)$ & $5(50.0)$ & $\begin{array}{c}0.750(0.14- \\
03.82) \\
\end{array}$ & $\begin{array}{c}2.439(0.12- \\
49.22)\end{array}$ \\
\hline Son/daughter & $6(42.9 \%)$ & $8(57.1 \%)$ & 1 & 1 \\
\hline \multicolumn{5}{|c|}{ Monthly income (birr) } \\
\hline$\leq 1000$ & $41(31.5 \%)$ & \begin{tabular}{|c|}
89 \\
$(68.5 \%)$ \\
\end{tabular} & \begin{tabular}{|c|}
$2.206(0.189-$ \\
$4.58)$ \\
\end{tabular} & $\begin{array}{c}1.087(0.3412- \\
2.86) \\
\end{array}$ \\
\hline $1000-2500$ & $20(46.5 \%)$ & $\begin{array}{c}23 \\
(53.5 \%) \\
\end{array}$ & $\begin{array}{c}1.073(0.41- \\
2.75)\end{array}$ & $0.76(0.27-2.15)$ \\
\hline$>2500$ & $14(48.3 \%)$ & $\begin{array}{c}15 \\
(51.7 \%) \\
\end{array}$ & 1 & 1 \\
\hline \multicolumn{5}{|c|}{ Length of stay in days } \\
\hline$\leq 8$ & $45(41.3 \%)$ & \begin{tabular}{|c|}
64 \\
$(58.7 \%)$ \\
\end{tabular} & $\begin{array}{c}0.67(0.380- \\
1.2) \\
\end{array}$ & $\begin{array}{c}0.65(0.33- \\
1.298) \\
\end{array}$ \\
\hline$>8$ & $30(32.3 \%)$ & $\begin{array}{c}63 \\
(67.7 \%)\end{array}$ & 1 & 1 \\
\hline
\end{tabular}

Table 2: Result of binary and multiple logistic regression analysis of variables with overall family satisfaction on the care of critically ill patient in ICU of governmental hospitals June 2017

shows younger families have more satisfaction. This difference may come due to the age category with the population is varied and the education of families in this study is higher in families less than age 35. Respondents primary school 3.13 times odds of more satisfied than families with higher education level (AOR 2.69, 95\% CI 0.971 7.472), (AOR 3.131, 95\% CI 1.163- 8.431) respectively. Also research in Portugal and Greece shows those with only basic education has more satisfaction than those having higher education. This could be the category of families have less demand and expectation. Families considering the patient health condition as worsening (73\%) and those who doesn't know the current status of the patient had (88\%) less odds of satisfaction than those families who believe the patient was in good progress by (AOR $0.27,95 \%$ CI $0.114-0.664$ ) and (AOR 0.12 , 95\% CI $0.04-0.378$ ) respectively. Similarly a study in Brazil shows families satisfaction were lower when the health condition of the patient become worsening. But in the studies in Washington and Switzerland the satisfaction of families of dying patient is higher than survivors.

This may be because dying patients are older and their families were getting more care and support from health professionals but in case of this study it may because a family of patients with critical case doesn't get any different care and support. Also can be affected by families' perception of satisfaction in relation with patient outcome. Because there was no literature in Ethiopia, the finding of the research failed to compare with other related literatures and the research has limitation on data in qualitative findings due to limited time and resource.

\section{Conclusion}

Majority of families were satisfied by the speed and coordination of health professionals in admission of patient and availability of physicians and nurses when the times of patient need help. Families had low satisfaction in information about the diagnosis and the procedure or tests performed and treatment of the patient. This may show limitedness of physician and nurse communication with families. Most respondents satisfied by noise. Level in ICU and they consider the quietness is comfortable for the patients. Families are list satisfied in sharing decision regarding patient care, this indicate that most decision about the patient is made by the health care providers. Families are not satisfied by peacefulness and comfort of waiting area. Generally the overall family satisfaction is moderate and variables like age, level of education and health condition of a patient significantly associated with satisfaction level.

\section{Ethical Consideration}

Ethical clearance obtained from IRB (institution review board) of Addis AbabaUniversity (AAU), School of allied health sciences, and department of nursing and midwifery. Formal letter of cooperation had written to Addis Ababa Health Bureau thento selected hospitals. Informed consent was obtained from each study participant after adequately providing information about the purpose, method, anticipated benefit of thestudy. Confidentiality was maintained by anon mous coding. During the data collection their privacy and comfort was ensured by preparing isolated environment.

\section{Acknowledgement}

Our gratitude goes to the Addis Ababa university school of Nursing for the approval of the ethical clearance. The authors would like to thank data collectors and supervisors for their commitment and the study participants for their valuable information.

\section{Funding}

Addis Ababa university school of nursing and midwifery. Availability of data and materials- the raw data would not be provided so as to protect patients anonymity. However, the summary data are available in the main document.

\section{References}

1. http://en.wikipedia.org/wiki/Intensive_care_unit. definition of ICU.

2. Winter (2013) Challenges in critical care in Africa: Perspectives and solutions ICU Manag \& Practice 12: 4

3. Azoulay E, Chaize M, Kentish-Barnes N (2014) Involvement of ICU families in decisions: Fine-tuning the partnership 4: 37

4. Towey RM, Ojara S (2008) Practice of intensive care in rural Africa. African Health Sci 8: 61-64.

5. www.ccnonline.org Al.ke. The Global ICU 2012.

6. Hendry R, Juma A, Lidenge SJ, Boniventura CT (2014) Disease patterns and 
Citation: Teshome GS, Roge NA, Ayalew YA, Sibany AS (2018) Family Satisfaction towards Care Provided to Criticaly III Patients and Associated Factors in the ICU of Governmental Hospitals of Addis Ababa Town, 2017. J Trauma Treat 7: 429. doi: 10.4172/2167-1222.1000429

Page 5 of 5

clinical outcomes of patients admitted in intensive care units of tertiary referral hospitals of Tanzania. Int Health Hum Rights 14: 26.

7. Tahir NA, Nega D, Abera K (2014) Levels of adult patients' satisfaction with nursing care in selected public hospitals in Ethiopia. Int J Health Sci 8: 371-379.

8. Heyland DK, Rocker GM (2002) Family satisfaction with care in the intensive care unit. Crit Care Med 30: 1413-1418.

9. Roberti SM, Fitzpatrick JJ (2010) Assessing family satisfaction with care of critically ill patients. Crit Care Nurse 30: 18-26.

10. Obeidant HM, Bond AE, Callister LC (2009) Parental experience having infant in new born Intensive Care Unit. J parent Educ 18: 23-29.

11. Celenza J, Conway J, Abraham M (2007) Advancing patient and family centered new born intensive care. Crit Care Med pp: 1-2.

12. Karlsson C, Tissel A, Engström A, Andershed B (2011) Family members' satisfaction with critical care: A pilot study. Crit Care Nurses 16: 1.

13. Dowling J, Vender J, Guilianelli S, Wang B (2005) Family-centered care and satisfaction predictors. CHEST 128: 81-92.

14. Neves FB, Dantas MP, Bitencourt AG, Vieira PS, Magalhães LT, et al. (2009) Analysis of family satisfaction in intensive care unit. Rev Bras Ter Intensiva 21: 32-37.

15. Sheaffer $H$ (2010) The met and unmet needs of families of patients in the ICU and implications for social work practiceSpring 5: 7 .
16. Latif A, Winters B, Berenholtz S, Holzmueller C (2010) Improving the quality of care in ICU. Surg Intensive Care Med pp: 861-871.

17. Jos M, Latour JB, Jan A (2008) Hazelet parental satisfaction in pediatric ICU. Pediatric Clinics of North America 55: 779-790.

18. Azoulay FP, Sylvie C, Mercé J, Caroline B, Bornstain C, et al. (2002) Impact of a family information leaflet on effectiveness of information provided to family members of intensive care unit patient. The American Thoracic Society.

19. Gries CJ, Curtis JR, Wall RJ, Engelberg RA (2008) Family member satisfaction with end-of-life decisionmaking in the Intensive Care Unit. CHEST 133: 704-712.

20. Stricker KH, Kimberger O, Schmidlin K, Zwahlen M, Mohr U, et al. (2009) Family satisfaction in the intensive care unit. Intensive Care Med 35: 2051-2059.

21. Azoulay E, Pochard F, Chevret S, Lemaire F, Mokhtari M (2001) Meeting the needs of families in Intensive Care Unit patient families: A multicenter study. Am J Respir Crit Care Med 163: 135-139.

22. Damghi N, Khoudri I, Oualili L, Abidi K, Madani N, et al. (2008) Measuring the satisfaction of intensive care unit patient families in Morocco: A regression tree analysis. Crit Care Med 133: 704-712.

23. Spyridoula NB, Konstantinosc A (2012) Factors affecting parental satisfaction in the neonatal Intensive Care Unit. J Neonatal Nurs 18: 183-192. 